\title{
Model of Solution Diffusions Through Membranes
}

\author{
Dušan Knežo \\ Department of Applied Mathematics and Informatics, Faculty of Mechanical Engineering, Letná 9, 04200 Košice, Slovak Republic
}

\section{BIOGRAPHICAL NOTES}

prof. RNDr. Dušan Knežo, CSc. is head of the Department of Applied Mathematics and Informatics He graduated at the Faculty of Natural Sciences, University of P.J. Šafarik in Košice. He received the PhD.-degree at the Mathematic-Physics Faculty, University of J.A. Comenius in Bratislava, and he was habilitated at the Faculty of Mechanical Engineering, University of Žilina, in the scientific branch of applied mathematics. His scientific focus is oriented to the modelling of processes in the biomedical engineering, to the research of materials, as well as to the measurement and diagnostic equipment, prognostics and evaluation of medical proceed. He is a co-author of one monograph, one academic textbook and author of several textbooks. He has published more than 60 papers in the scientific journals and in the proceedings of the conferences and he has more than 80 quotations concerning his professional works. He was also incorporated in various grant research projects and industrial projects.

\section{KEYWORDS}

Osmosis, solution, membrane, differential equation.

\section{ABSTRACT}

There is created in this paper a model of the diffuse drainage of solutions through the membranes. The possibilities of such process simulations using of the differential equations are presented in this article as well.

\section{Introduction}

Diffusion of various solutions through membranes is a phenomenon occurring often in the biomedical procedures and also in other processes. There was created a simple mathematical model in the work [2], which enables to determine time behaviour of the solution concentration during the diffusional seepage. This work presents a mathematical model taking into the consideration an influence of various parameters on the diffusional process.

\section{Mathematical Model}

There is given a vessel, which is divided into two individual parts $V_{1}$ and $V_{2}$ by means of a membrane with the surface area $S$. The solution, which is prepared from the same matter, is situated in each of these two parts, whereas the level height is the same in both parts (Fig. 1), as well as the solution temperature is identical in the given volumes.

Let in the time $t_{0}=0$ the solution concentration in the part $V_{1}$ equals to $A$ and in the part $V_{2}$ it is $B$, where as $A \neq B$. If the solution concentration in the part $V_{1}$ is $K_{1}(t)$ in the time $t, t \geq 0$ and in the part $V_{2}$ this concentration is $K_{2}(t)$, so it is: 


$$
\begin{aligned}
& K_{1}(0)=A, \\
& K_{2}(0)=B .
\end{aligned}
$$

Because of $A \neq B$, the solution concentration is different in the individual parts. From this reason there is occurring a phenomenon of the diffusional seepage of the matter and in this way the final concentrations will be equalized in the both parts gradually.

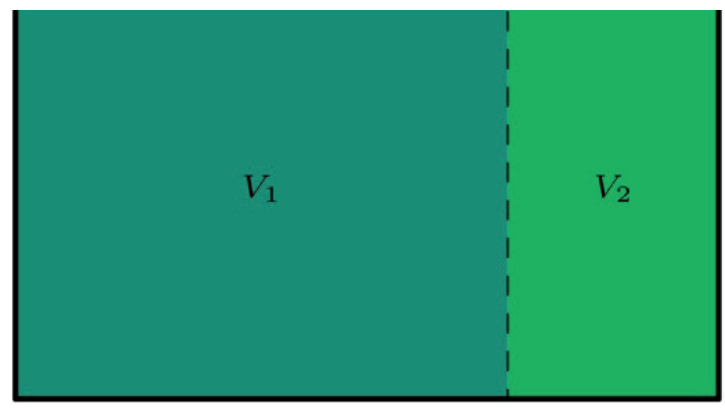

Fig. 1: Vessel divided with membrane.

There are taken into consideration also the next conditions:

- the change of concentration in the part $V_{1}$ is directly proportional to the difference $K_{2}(t)-K_{1}(t)$ and the change of concentration in the part $V_{2}$ is directly proportional to the difference $K_{1}(t)-K_{2}(t)$, - the change of concentration in the part $V_{1}$ is directly proportional to the ratio $V_{2} / V_{1}$ and the change of concentration in the part $V_{2}$ is directly proportional to the ratio $V_{1} / V_{2}$ (value of the ratio $V_{2} / V_{1}$ or ratio $V_{1} / V_{2}$ has an influence on the concentration change speed in the individual parts, but it has also an impact on the concentration in the steady status, i.e. for the $t \rightarrow \infty$ ),

- the change of concentration in the both parts is directly proportional to the value of the membrane surface area $S$,

- the speed of diffusion is directly proportional to the value $e^{-\frac{c}{T}}$, where $c>0, T$ is the temperature of solution (in the case of the absolute zero temperature the diffusional speed equals to the zero value and, on the other side, the highest speed could be obtained at the level of infinitely high solution temperature).

Taking into consideration the above-mentioned assumptions the concentration changes during the time interval from $t$ to $t+\Delta t$ will be described by the equations:
$K_{1}(t+\Delta t)-K_{1}(t)=\alpha \cdot \frac{V_{2}}{V_{1}} \cdot S \times$

$\times e^{-\frac{c}{T}} \cdot\left(K_{2}(t)-K_{1}(t)\right) \cdot \Delta t$,

$K_{2}(t+\Delta t)-K_{2}(t)=\beta \cdot \frac{V_{1}}{V_{2}} \cdot S \times$

$\times e^{-\frac{c}{T}} \cdot\left(K_{1}(t)-K_{2}(t)\right) \cdot \Delta t$,

where the coefficients $\alpha, \beta, \alpha, \beta>0$, are the real numbers. The values of these coefficients characterize the diffusional speed in the corresponding direction. The equations (3) and (4) will be modified:

$$
\begin{aligned}
& \frac{K_{1}(t+\Delta t)-K_{1}(t)}{\Delta t}= \\
& =\alpha \cdot \frac{V_{2}}{V_{1}} \cdot S \cdot e^{-\frac{c}{T}} \cdot\left(K_{2}(t)-K_{1}(t)\right), \\
& \frac{K_{2}(t+\Delta t)-K_{2}(t)}{\Delta t}= \\
& =\beta \cdot \frac{V_{1}}{V_{2}} \cdot S \cdot e^{-\frac{c}{T}} \cdot\left(K_{1}(t)-K_{2}(t)\right) .
\end{aligned}
$$

From the equations (5) and (6), using a limit transformation for the $\Delta t \rightarrow 0$, we obtain:

$$
\begin{aligned}
& \lim _{\Delta t \rightarrow 0} \frac{K_{1}(t+\Delta t)-K_{1}(t)}{\Delta t}=\alpha \cdot \frac{V_{2}}{V_{1}} \times \\
& \times S \cdot e^{-\frac{c}{T}} \cdot\left(K_{2}(t)-K_{1}(t)\right) \cdot \Delta t, \\
& \lim _{\Delta t \rightarrow 0} \frac{K_{2}(t+\Delta t)-K_{2}(t)}{\Delta t}=\beta \cdot \frac{V_{1}}{V_{2}} \times \\
& \times S \cdot e^{-\frac{c}{T}} \cdot\left(K_{1}(t)-K_{2}(t)\right) \cdot \Delta t,
\end{aligned}
$$

thus:

$\frac{d K_{1}}{d t}=\alpha \cdot \frac{V_{2}}{V_{1}} \cdot S \times$

$\times e^{-\frac{c}{T}} \cdot\left(K_{2}(t)-K_{1}(t)\right)$,

$\frac{d K_{2}}{d t}=\beta \cdot \frac{V_{1}}{V_{2}} \cdot S \times$

$\times e^{-\frac{c}{T}} \cdot\left(K_{1}(t)-K_{2}(t)\right)$.

If we postulate that the temperature value $T$ is constant and if we designate:

$$
\begin{aligned}
& \alpha^{*}=\alpha \cdot \frac{V_{2}}{V_{1}} \cdot S \cdot e^{-\frac{c}{T}}, \\
& \beta^{*}=\beta \cdot \frac{V_{1}}{V_{2}} \cdot S \cdot e^{-\frac{c}{T}}
\end{aligned}
$$


so we obtain a system of the differential equations:

$$
\begin{aligned}
& \frac{d K_{1}}{d t}=\alpha^{*} \cdot\left(K_{2}(t)-K_{1}(t)\right), \\
& \frac{d K_{2}}{d t}=\beta^{*} \cdot\left(K_{1}(t)-K_{2}(t)\right),
\end{aligned}
$$

what is a system of two linear differential equations with the constant coefficients. This system can be solved by means of the elimination method.

From the equation (11) it is expressed $K_{2}(t)$ :

$$
K_{2}(t)=\frac{1}{\alpha^{*}} \cdot \frac{d K_{1}(t)}{d t}+K_{1}(t)
$$

Using derivation of the equation (13), together with application of the relations (12) and (13), we obtain:

$$
\frac{d^{2} K_{1}}{d t^{2}}=-\left(\alpha^{*}+\beta^{*}\right) \cdot \frac{d K_{1}}{d t},
$$

or

$$
\frac{d^{2} K_{1}}{d t^{2}}+\left(\alpha^{*}+\beta^{*}\right) \cdot \frac{d K_{1}}{d t}=0
$$

The equation (14) is a homogeneous linear differential equation of the $2^{\text {nd }}$ order. Its characteristic equation is:

$r^{2}+\left(\alpha^{*}+\beta^{*}\right) \cdot r=0$.

The roots of the characteristic equation (15) are $n_{1}=0$ and $r_{2}=-\left(\alpha^{*}+\beta^{*}\right)$. Consequently the general solution of the equation (14):

$$
K_{1}(t)=c_{1}+c_{2} e^{-\left(\alpha^{*}+\beta^{*}\right) t} .
$$

Considering

$$
\frac{d K_{1}}{d t}=-c_{2}\left(\alpha^{*}+\beta^{*}\right) e^{-\left(\alpha^{*}+\beta^{*}\right) t},
$$

thus there is following from the relations (13), (16) and (17):

$$
K_{2}(t)=c_{1}-\frac{\beta^{*}}{\alpha^{*}} c_{2} e^{-\left(\alpha^{*}+\beta^{*}\right) t} .
$$

So, the general solution of the system (7), (8) is:

$$
K_{1}(t)=c_{1}+c_{2} e^{-\left(\alpha^{*}+\beta^{*}\right) t},
$$

$K_{2}(t)=c_{1}-\frac{\beta^{*}}{\alpha^{*}} c_{2} e^{-\left(\alpha^{*}+\beta^{*}\right) t}$.

Applying the initial conditions (1), (2), afterwards from the relations (19) and (20) for the constants $c_{1}$ and $c_{2}$ it is following:

$A=c_{1}+c_{2}$,

$B=c_{1}-\frac{\beta^{*}}{\alpha^{*}} \cdot c_{2}$.

From these:

$c_{1}=\frac{A \beta^{*}+B \alpha^{*}}{\alpha^{*}+\beta^{*}}$,
$c_{2}=\alpha^{*} \cdot \frac{A-B}{\alpha^{*}+\beta^{*}}$.

Such that the general solution of the system (11), (12), which fulfils the initial conditions (1), (2), is:

$K_{1}(t)=\frac{A \beta^{*}+B \alpha^{*}}{\alpha^{*}+\beta^{*}}+\alpha^{*} \cdot \frac{A-B}{\alpha^{*}+\beta^{*}} e^{-\left(\alpha^{*}+\beta^{*}\right) t}$,

$K_{2}(t)=\frac{A \beta^{*}+B \alpha^{*}}{\alpha^{*}+\beta^{*}}+\beta^{*} \cdot \frac{B-A}{\alpha^{*}+\beta^{*}} e^{-\left(\alpha^{*}+\beta^{*}\right) t}$.

With regard to the (9), (10) we obtain for a solution:

$K_{1}(t)=\frac{\beta A V_{1}^{2}+\alpha B V_{2}^{2}}{\alpha V_{2}^{2}+\beta V_{1}^{2}}+$

$+\alpha \cdot V_{2}^{2} \cdot \frac{A-B}{\alpha V_{2}^{2}+\beta V_{1}^{2}} \times$

$\times \exp \left(-\frac{S e^{-\frac{c}{T}}}{V_{1} V_{2}} \cdot\left(\alpha V_{2}^{2}+\beta V_{1}^{2}\right) \cdot t\right)$,

$K_{2}(t)=\frac{\beta A V_{1}^{2}+\alpha B V_{2}^{2}}{\alpha V_{2}^{2}+\beta V_{1}^{2}}+$

$+\beta \cdot V_{1}^{2} \cdot \frac{B-A}{\alpha V_{2}^{2}+\beta V_{1}^{2}} \times$

$\times \exp \left(-\frac{S e^{-\frac{c}{T}}}{V_{1} V_{2}} \cdot\left(\alpha V_{2}^{2}+\beta V_{1}^{2}\right) \cdot t\right)$.

It is evident from the relations (21) and (22) that in such part of the vessel, where the original concentration level was higher; it will be sinking exponentially and in the part with the lower original concentration this will be increasing exponentially (Fig. 2). 


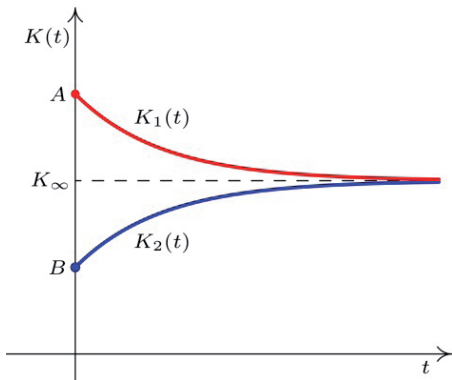

Fig. 2: Time behaviour of the concentrations for $A>B, V_{1} / V_{2}$ and $S=S_{0}$

It is also evident from the relations (21) and (22) that:

$$
\begin{aligned}
& \lim _{t \rightarrow \infty} K_{1}(t)=\frac{\beta A V_{1}^{2}+\alpha B V_{2}^{2}}{\alpha V_{2}^{2}+\beta V_{1}^{2}}, \\
& \lim _{t \rightarrow \infty} K_{1}(t)=\frac{\beta A V_{1}^{2}+\alpha B V_{2}^{2}}{\alpha V_{2}^{2}+\beta V_{1}^{2}} .
\end{aligned}
$$

According to the above-mentioned relations it is possible to say that after a sufficiently long time (after an infinite time theoretically) the concentration levels in both parts of the vessel will be settled on the common level

$$
K_{\infty}=\frac{\beta A V_{1}^{2}+\alpha B V_{2}^{2}}{\alpha V_{2}^{2}+\beta V_{1}^{2}} .
$$

Influence of the values $V_{1}$ and $V_{2}$ on the diffusion process is evident from the Fig. 3 and Fig. 4.

Analogically, an influence of the $S$ value on the diffusion process is clear from comparison of the figures Fig. 2 and Fig. 5.

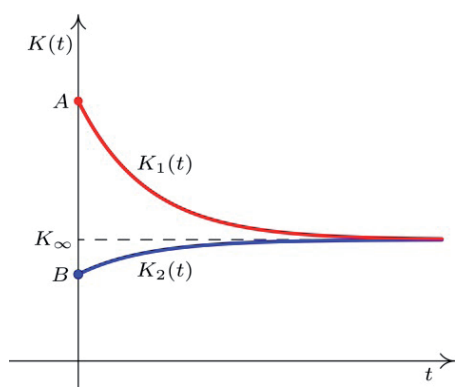

Fig. 3: Time behaviour of the concentrations for $A>B, V_{1} / V_{2}=1 / 2$ and $S=S_{0}$

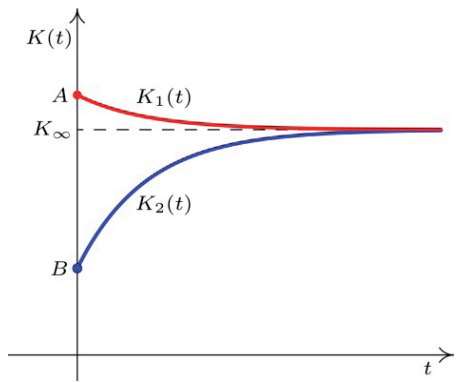

Fig. 4: Time behaviour of the concentrations for $A>B, V_{1} / V_{2}=2$ and $S=S_{0}$

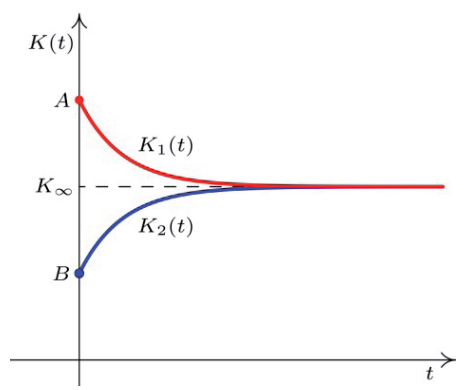

Fig. 5: Time behaviour of the concentrations for $A>B, V_{1} / V_{2}=1$ and $S=2 . S_{0}$

\section{Conclusion}

This presented model of the diffused material transport through a membrane takes into the consideration an influence of various parameters that are affecting the speed of the diffusion process running. Therefore it is possible to suppose that this model is able to describe the time behaviour of the concentrations quite exactly. However, this assumption has to be verified by means of an experiment.

This work is the result of the project implementation: Centre for research of control of technical, environmental and human risks for permanent development of production and products in mechanical engineering (ITMS: 26220120060) supported by the Research \& Development Operational Programme funded by the ERDF.

\section{References}

[1] Amelkin, V. V: Diferencial'nyje uravnenija $\vee$ priloženijach. Nauka, Moskva, 1987.

[2] Knežo, D.: O modelovaní osmózy pomocou diferenciálnych rovníc Transfér inovácií č. 24 (2012), s. 27-29, ISSN 1337-7094.

[3] Ponomarev, K. K.: Sostavlenije diferencialnych uravninij. Vyšejšaja škola, Minsk. 1973.

[4] Weisstein, E. W.: Differential Equation. http://mathworld.wolfram com/DifferentialEquation.html. 